\title{
El carácter varonil \\ (y otras cualidades afines) de la lengua de Castilla: fundamentos fonéticos de un tópico antiguo*
}

The manly character (and other related qualities) of the Castilian Spanish: phonetic foundations of an ancient stereotype

Francesca Dalle Pezze

Universidad de Verona,

Departamento de Lenguas

y Literaturas Extranjeras

francesca.dallepezze@univr.it
Renzo Miotti Universidad de Verona, Departamento de Lenguas y Literaturas Extranjeras renzo.miotti@univr.it 


\section{Resumen}

El tópico áureo del carácter varonil del castellano tiene antigua tradición en España, ya que se remonta aun a la contraposición entre el latín de Roma y el de Hispania: observaciones en las que se aúnan los conceptos de marcialidad y varonilidad - pero también otros rasgos distintivos, estrechamente relacionados - constituyen una cadena que se extiende a lo largo de la historia de las ideas lingüísticas. Nuestro propósito es proponer algunas reflexiones, a partir de testimonios antiguos, sobre la que se denominaría, en términos sociolingüísticos, actitud afectiva -que se manifiesta a través de una adjetivación recurrente-, para después comparar dichas reflexiones con las modernas descripciones fonéticas. Pese a que solo en contados casos las fuentes ofrecen referencias explícitas a rasgos fonéticos concretos, es posible, sin embargo, aislar algunos: elementos perfectamente observables, como la consonante vibrante múltiple, que denota expresividad y fuerza y representa una de las características más antiguas de la lengua, ya que respalda un papel activo de las lenguas prerromanas (concretamente el vasco) en el rostro sonoro del español.

Palabras clave: Marcial; castellano; consonante vibrante; ajustes articulatorios; sustrato vasco

\section{Abstract}

The golden stereotype of the male-oriented character of Castilian has an ancient tradition in Spain, dating back to the contrast between the Latin of Rome and that of Hispania. Observations that combine the concepts of martialism and manliness - and other closely related distinctive features constitute a chain that spans throughout the history of linguistic ideas. The aim of our work is to propose some reflections, based on ancient testimonies, on what would be called, in sociolinguistic terms, an affective attitude - which manifests itself through recurrent adjectives — and then compare these reflections with modern phonetic descriptions. Although the sources offer explicit references to specific phonetic features in only a few cases, it is nevertheless possible to isolate some of them. These are evident elements, such as the multiple vibrant consonants denoting expressiveness and force as one of the oldest characteristics of the language. This illustrates the active role of pre-Roman languages (specifically Basque) in the vibrant sounds of Spanish.

Keywords: Martial; Castilian; trill consonant; voice quality; Basque substrate 


\section{Los nomina duriora' de Marcial}

A partir de la temprana Edad Moderna, en España era frecuente la mención, en textos de carácter histórico y filológico, de ciertos versos del poeta Marcial, que se referían a la asperidad de los topónimos celtíberos:

[...] nos Celtis genitos et ex Hiberis

nostrae nomina duriora terrae

grato non pudeat referre versu $[\ldots]$

Haec tam rustica, delicate lector, rides nomina? Rideas licebit, haec tam rustica malo quam Butuntos. ${ }^{2}$ (Martialis, 1969, IV: LV)

En este epigrama el poeta bilbilitano subrayaba con orgullo su procedencia del interior de Hispania — tierra ruda y tosca— haciendo hincapié en la contraposición entre "la robusta naturalità spagnola e la desolante artificiosità della vita di Roma" (Citroni, 2002: 291).

Posiblemente los antiguos topónimos de Hispania resultaran duros a los escritores latinos por su exotismo y su inherente dificultad —Plinio, según Bernardo de Aldrete (2002 [1606]: 168), "dexó de escribir muchos nombres de España por la dificultad que auia en pronunciarlos". No es nuestra intención entrar en el terreno de la toponimia peninsular de origen prerromano (cel-

* El estudio es el fruto de planteamientos metodológicos comunes a ambos autores. Sin embargo, el §1 corre a cargo de Francesca Dalle Pezze, el $\S 3$ de Renzo Miotti, el $\S 2$ y el $\S 4$ de ambos. Asimismo, las traducciones a lo largo de todo el texto son de ambos autores.

1 En el epigrama IV, LV los nomina duriora se refieren a topónimos, orónimos e hidrónimos celtíberos, algunos ubicados en los alrededores de Bilbilis (la actual Calatayud), suelo natal de Marcial.

2 "No nos dé vergüenza, a nosotros los descendientes de los celtíberos, recordar con gratitud en nuestros versos los rudos nombres de nuestro país [...] Lector delicado, ¿te ríes de estos nombres tan rudos? Adelante, ríete, estos nombres tan rústicos yo los prefiero a Bitonto.” 
tibérico, en el caso específico de Marcial); el principal interés de los versos citados estriba en que posiblemente constituyen uno de los primeros testimonios de lo que se denominaría una actitud afectiva. ${ }^{3}$ Dicha actitud se manifiesta asociando una lengua, o variedad de lengua, con una cualidad, en este caso negativa (aunque expresada con orgullo, como hemos dicho): el carácter tosco de las lenguas prerromanas y, en general, de lo hispánico — que seguirá reverberando, y esto es lo que importa subrayar, en lo castellano.

Los comentarios sobre los versos de Marcial hechos a lo largo de los siglos, se insertan en las laudes Hispaniae, ${ }^{4}$ que - como resume Gil (2004: 234-235) — fueron forjando la idea de una conexión mítica entre la España de la época y la Hispania romana. A partir de finales del siglo XVI, además, empezó a ser objeto de loor el sistema lingüístico mismo del romance, frente a las épocas anteriores que centraban el encomio más bien en las letras (Binotti, 1995: 29).

El propósito primordial de nuestro trabajo es el de remontarnos a los orígenes del muy conocido tópico áureo del carácter varonil de la lengua castellana - de antigua raigambre, como acabamos de ver-, observar su desarrollo a través de los comentarios que se hicieron de los versos de Marcial a lo largo de los siglos, así como de las reflexiones metalingüísticas de gramáticos y eruditos sobre el carácter de la lengua castellana, y comparar dichos comentarios y reflexiones con las modernas consideraciones de tipo fonético, para intentar explicar en qué rasgos prominentes estribaría la percep-

3 En sociolingüística, la actitud lingüística se define como la "manifestación de la actitud social de los individuos, distinguida por centrarse y referirse específicamente tanto a la lengua como al uso que de ella se hace en la sociedad" (Moreno Fernández, 2005: 178).

4 Las laudes Hispaniae, que se consideran directas descendientes del discurso demostrativo clásico (Binotti, 1995: 10), fueron textos de carácter histórico que, a partir del Renacimiento, describieron hechos heroicos, grandezas, cosas notables y cualidades de los españoles con el fin de ensalzar la lengua y las letras nacionales. 
ción del castellano como lengua varonil. Este estereotipo suponía que la lengua de Castilla se considerara varonil por su aspereza, marcialidad, sonoridad y majestuosidad, rasgos atribuidos tradicionalmente al talante o a la conducta del varón prototípico - frente a otras lenguas extranjeras que sonarían como más muelles y, por lo tanto, afeminadas. No se trataba tanto de una contraposición de género dentro de la comunidad lingüística de los hispanohablantes, sino de un parangón, a menudo orgullosamente esgrimido, con respecto a las demás naciones. Asimismo, comentaremos otros rasgos relacionados con el carácter varonil de la lengua castellana, que emergen de comentarios de autores de siglos pasados, y que, en nuestra opinión, hay que considerar como estrechamente relacionados con dicha apreciación.

En este apartado reseñaremos someramente algunas atestiguaciones de la difusión de los versos del poeta bilbilitano, empezando por la mención que de ellos hace a comienzos del siglo XVII Bernardo de Aldrete en Del origen y principio de la lengua castellana (2002 [1606]: 168): "de la dureza, i dificultad destos nombres haze memoria Marcial". En un capítulo dedicado a los vocablos antiguos que usaron los españoles antes de la venida de los romanos, el erudito andaluz enumera una serie de comentarios procedentes de autores latinos que apuntan hacia la dificultad de la lengua de la Hispania romana, a saber, Cicerón, Plinio, Pomponio Mela y el mismo Marcial. A pesar de que esta recurrencia podría deberse a un simple expediente retórico, ya que - como indica Correa Rodríguez (2002: 133) a propósito de Plinio y su descripción de la Bética - "no es creíble que a más de dos siglos de distancia de la conquista haya topónimos de 'incómoda pronunciación' en una región profundamente romanizada", conviene destacar su cada vez más tangible presencia en el discurso metalinguiístico sobre España y lo español, se fundamente o no en datos ciertos.

Pocos años después, bajo la voz lengua de su Tesoro, Sebastián de Covarrubias Orozco (2006 [1611]: 1179-1180) afirma: 
La lengua antigua española debió ser difícil y áspera de pronunciar a los forasteros y por esta razón se debe estimar, siendo lengua varonil. Marcial, hablando della y de sus vocablos groseros, dice lib. 4, epigrama 55, ad Lucium, 'Luci gloria', etc., ibi:

Rides nomina? rideas licebit,

Haec, tam rustica, delicate lector,

Haec tam rustica malo quam Britannas. ${ }^{5,6}$

Es interesante destacar en este alegato la conexión que establece Covarrubias entre la supuesta distancia fonética de la lengua hispánica anterior a la romanización con respecto al latín (y la tosquedad de sus vocablos) y el carácter varonil que resulta de estas peculiaridades. En efecto, a través de esta afirmación, Covarrubias engarza el tópico áureo de este carácter (véase § 2) con una supuesta raigambre antigua, lo que constituiría una clara manifestación del genio del idioma, inmutable a lo largo de los siglos.

Remitiendo a Pomponio Mela, hacia finales de siglo el jesuita Gabriel de Henao (1689: 143) comenta los mismos versos y añade otros, tomados de dos epigramas del poeta bilbilitano que refrendan semejante concepto. Del primero (XII, XVIII) menciona los siguientes versos: "Celtiberis I haec sunt nomina crassiora terris", que traduce así: "Estos son los nombres muy groseros de Celtiberia". Y añade: "Habla, templandose à la delicadez, y pronunciacion de los Romanos". Del segundo (X, LXV) indica los versos

Cur frater tibi dicor, ex Iberis, et Celtis genitus, Tagique civis?

$[\ldots]$

5 "Lector delicado, ¿te ríes de estos nombres tan rudos? Adelante, ríete, estos nombres tan rústicos yo los prefiero a Britania."

6 Prescindimos aquí de la cuestión de la variante Britannas, en vez de Butuntos, por no adentrarnos en problemas filológicos ajenos a nuestro enfoque. 
Tu flexa nitidus coma vagaris,

Hispanis ego contumax capillis.

$[\ldots]$

Os blesum tibi, debilisque lingua est,

Nobis filia fortius loquetur.

de los que ofrece la siguiente paráfrasis: "Porquè me llamas hermano, siendo yo natural de Celtiberia, y ciudadano del Tajo? Tu te paseas brillante con los crespos, y enrizados cabellos; yo descompuesto, como Español. Tu tienes tartamuda, y delicada lengua; mi hija, aun pequeña, hablará con mayor dureza". Tal vez por pudor o porque no es pertinente a su discurso, el padre Henao no comenta todo el epigrama que, sin embargo, posee connotaciones sexuales evidentes, puesto que contrapone la rudeza hispánica a la afeminación del destinatario del epigrama, un ciudadano de Corinto.

Según la transcripción del padre Henao, el epigrama hace referencia a una hija que, por ser hispánica también, habla con mayor dureza aun siendo una niña. Aunque esta versión difiere de otras transcripciones que incluyen ilia ('caderas', 'ingles', 'vientre') en vez de filia, lo que cabe resaltar en esta interpretación es el carácter varonil que supuestamente poseen los hispánicos en su conjunto, prescindiendo del sexo. ${ }^{7}$ Esta misma condición es la que ha llegado a la observación de Navarro Tomás: "Reducida a la proporción correspondiente al lenguaje femenino, esta cualidad [el carácter varonil] se manifiesta asimismo en el habla de la mujer castellana" (1935: 22).

En el siglo XVIII el padre fray José de San Juan, en la Aprobación a la Bibliotheca universal de la polygraphia española de Cristóbal Rodríguez, se sirve del antiguo poeta Marcial para modernos propósitos casticistas:

7 Un detallado comentario de este epigrama puede leerse en Alfayé Villa (2013: 52-60), quien, además, menciona la variante fistula en lugar de filia. 
Y que Marcial aviendo vsado en vn Epigrama muchas vozes Antiguas, y Españolas, como Graium, Rixama, Peteron, Petusia, y otras; concluye diziendo, que quiere mas vsar aquellas vozes, por mas que a quien no las entiende, le suenen Barbaras, sabiendo son de su Idioma originario, que andar mendigando terminos mas pulidos en los forasteros. [...] Harta reprehension, de que deben darse por entendidos, los que nos entrometen en el Lenguage mil vozes estrañas, à titulo de enriquecer la Lengua, y no consideran estos Contravandistas de Vocablos, que para tomarse esta licencia debian probarnos primero el Dogma Pithagorico, mostrando que informan sus Cuerpos las Almas de Hortensio, de Gongora, ò de otros tan grandes, si es que ha avido, en esta Cathegoria tan grandes otros. (Rodríguez, 1738: Aprobación)

En el siglo siguiente el historiador y epigrafista Fidel Fita, partidario del vascoiberismo, afirmaba: "Aquellos nombres de su querida pátria, que no obstante la aspereza del sonido eran tan dulces al corazón del poeta Bilbilitano, se explican, parte por el celta, parte por el vascuence, y parte, en fin, por ambos idiomas á la vez; puesto que uno y otro (á mi ver), no son sino diferentes ramas de un mismo tronco aryo, si bien brotaron en diferentes épocas" (Fita y Colomé, 1879: 53). Más adelante, el padre Fita llega a vincular el timbre claro y majestuoso del castellano a su ascendencia vasca:

Se ve en el vascuence la lengua que lanza su timbre limpio y puro por entre lábios finos y de ordinario abiertos, al paso que esta propiedad va oscureciéndose gradualmente desde el Gael al címrico; á la manera que el acento castellano, claro, fijo y majestuoso, tendiéndose por la Península apaga su brillantez ó se enturbia en boca de Valencianos y Catalanes, Gallegos y Portugueses. (Fita y Colomé, 1879: 68)

8 Volveremos sobre la cuestión de las lenguas de sustrato en $\S 3$. 
Los versos de Marcial siguieron fascinando a los filólogos del siglo Xx, sobre todo en la estela de la enseñanza pidalina, como se puede comprobar en obras como el estudio de Galmés de Fuentes (2000: 5), donde aparecen a manera de epígrafe junto a aquel conocidísimo poema de Miguel de Unamuno (1966) que engarza topónimos españoles. ${ }^{9}$

\section{El carácter varonil y marcial del castellano en la historia de las ideas lingüísticas: un breve excurso}

Dentro de los testimonios más antiguos acerca de la aspereza y marcialidad del castellano, el Poema de Almería ocupa un lugar destacado. Compuesto probablemente por un monje leonés a mediados del siglo XII, el poema indica las características fonéticas del castellano equiparándolas al sonido de una trompeta y de un tambor: "illorum lingua resonat quasi tympano tuba" (Rodríguez Aniceto, 1931: 155). Como resume Zamora Salamanca (2008: 1-2), esta similitud ha despertado el interés de los lingüistas desde Ramón Menéndez Pidal hasta Tomás Navarro Tomás, Amado Alonso y Roger Wright. Es precisamente Navarro Tomás, en su discurso de ingreso en la Academia de la Lengua Española, quien señala el aire "digno, marcial y varonil" del castellano (1935: 40). ${ }^{10} \mathrm{Ob}-$ servaciones de esta naturaleza representan los últimos eslabones de una cadena que se extiende a lo largo de la historia de las ideas lingüísticas, que a su vez remite a numerosos testimonios antiguos del vínculo entre los caracteres fonéticos del castellano y su talante varonil.

9 Se trata del poema “Ávila, Málaga y Cáceres”, en Obras completas, vi, 1036, 12 de julio de 1928.

10 Emilio Castelar ofreció una apreciación análoga en su discurso de recepción pública ante la Corporación en 1880, en el cual afirmaba que la lengua española es: "dulce como la melodía más suave y retumbante como el trueno más atronador" (Castelar, 1880: 114). 
El antes mencionado Bernardo de Aldrete afirmaba, a este propósito, que en la lengua castellana "buscamos suauidad y dulçura, ella la tiene acompañada de gran ser y magestad, conuiniente a pechos varoniles, y nada afeminados" (de Aldrete, 2002 [1606]: 369). En su Arte de la lengua española castellana, Gonzalo Correas (1954 [1625]: 490-491) sostenía que la lengua latina es "no poco escabrosa" por la presencia de sílabas duras y concatenaciones como trans, post, dens, urbs, stirps, saxum, stant, mientras que la castellana, que "no tiene nada de esos tropiezos, ni vazios, i corre más bien sonora i grave, i mas llena en boz i suave en su orazion", es "igual, entera i de mucha enerxia, i enfasis en sus frases". Correas concluía denotando "la habla Española por varonil".

Asimismo, la idea del carácter varonil dejó varias atestiguaciones en el siglo siguiente por mano de autores como Benito Jerónimo Feijoo, Benito de San Pedro, Tomás de Iriarte y José de Vargas Ponce, según puede apreciarse en los textos siguientes: "Es cierto que los Franceses pronuncian más blando, los Españoles más fuerte. La lengua Francesa (digámoslo así) se desliza: la Española golpea. [...] más razón habría de conceder el exceso al Castellano: siendo prenda más noble del idioma una valentía varonil, que una blandura afeminada." (Feijoo, 1778 [1726], XV: §17); "Iva ella creciendo entre tan ilustres ingenios, i volando azia las mas encumbrada perfeccion. Pero aun quedava que hacer. Se le avia de dar mayor dulzura, i fuerza para que se hallasse del todo agradable i varonil." (de San Pedro, 1769: 82-83); "Pues si fuera de Italia me desvelo I En buscar un lenguage I Que á tódos para el canto se aventaje, I En el Hispano suelo I Le encuentro noble, rico, magestuoso, / Flexîble, varonil, harmonïoso." (de Iriarte, 1779: 124-125); "El italiano mismo, para de una vez llegar al competidor mas temible, no puede en su prosa mantenerse contra tanta ventaja de la nuestra: contra la linda multitud de sus varias terminaciones, y aquella medida económica de consonantes y vocales, y contra su pronunciacion varonil y llena.” (de Vargas Ponce, 1793: 95).

El gaditano de Vargas Ponce — que ingresaría años más tarde en la Real Academia Española— subraya de forma más explícita 
aún el carácter varonil del castellano cuando afirma que es más apto que el italiano para las órdenes militares: "Siguiendo el mismo exemplo de arriba, al oir: Presentate l'armi: Prepararsi á caricare, etc. parece que si gl'inimici no se mueren de risa, no deben temer otro daño. [...] las voces Atencion, Armas al hombro, Carguen, Fuego, llevan en sí la entereza y brío adequados á su destino" (de Vargas Ponce, 1793: 95-96).

En su "Apéndice sobre el genio, idiotismos, edades y autores célebres de la lengua castellana" — contenido en la Gramática de la lengua castellana-, el presbítero y docente andaluz Agustín Muñoz Álvarez (1828 [1793]: 21) afirmaba que "[1]a pronunciación de la lengua castellana es clara, llena, moderadamente suave, y variada, cual convenía á la gravedad de los españoles para sostener un tono firme y varonil".

El tópico llega, finalmente, a las obras de la Real Academia Española, que - a propósito de la costumbre de algunos impresores de escribir la sílaba ex como es- en el prólogo del diccionario de 1837 declara: "so color de suavizar la pronunciación de las indicadas sílabas, se desvirtúa y afemina en cierto modo la noble y varonil robustez en nuestro idioma".

Medio siglo después (1866), en su discurso de ingreso el académico Miguel Mir afirmaba: "Porque España fué grande [...], por esto su lengua fué grande también y llena de dignidad y hermosura, no de hermosura muelle y afeminada, sino grave, severa y varonil, cual convenía á la que se había formado en aquellos pechos robustísimos y á la que era eco de aquellas almas indomables que habían vencido y avasallado el mundo" (Mir, 1866: 41). Poco antes, el inspector de primera enseñanza de la provincia de Lérida, Rafael Monroy, escribía: "la lengua castellana [...] es naturalmente robusta y varonil en su pronunciación" (1865: 77).

El afeminamiento y pérdida de energía de la lengua de su época preocupaba a muchos escritores y gramáticos, como Pedro Muñoz Pena, que en su Discurso sobre el origen y progreso de la lengua castellana afirmaba: "Verdad es que esta poesía erudita y cortesana no pudo resistir á la decadencia por mucho tiempo, y ha 
no haberle prestado la popular sus no corrompidos acentos y varonil entonación, ella se hubiera despeñado en el precipicio del enigma y en la oscuridad del logogrifo" (2010 [1872]: 41). Quejas como esta explotaban la idea de la corrupción de la lengua inoculada por las costumbres extranjerizantes y subrayaban decididamente la pureza de la veta popular, ese talante pulcro y auténtico capaz de sobrevivir a lo largo de los siglos.

El concepto de virilidad acabará asociándose no solamente a la lengua sino a todo el solar castellano cuando, hacia finales del siglo XIX, empezó a fraguarse el paralelo simbólico entre el paisaje y el talante del pueblo que lo habita. ${ }^{11}$ Bajo esa lupa hay que leer la contraposición que establece Francisco Giner de los Ríos entre el paisaje gallego - dulce y por lo tanto femenino- y el castellano - rudo y por lo tanto masculino-, como señala Ortega Cantero (2009: 35):

Aquí, por el contrario, asoma por doquiera el esfuerzo indomable que intenta abrirse paso a través de obstáculos sin cuento; y así como en un mismo día y lugar se suceden con rapidez vertiginosa el hielo y el ardor de los trópicos, así también el sol deslumbra con un fulgor casi agrio en el fondo de un cielo, de puro azul, casi negro. Es la nota varonil, masculina, que pudiera llamarse. (Giner de los Ríos, 2004 [1886]: 796)

Por su parte, Tomás Navarro Tomás, discípulo de Menéndez Pidal, retoma la noción del genio inmutable del idioma: "Sobre el carácter varonil del acento castellano se encuentran, asimismo, en los escritores extranjeros numerosas referencias. En ellas se hace notar repetidamente que la contextura fonética de dicho acento le permi-

${ }^{11}$ Fue Antonio Machado (1991 [1917]: 112) quien aquilataría este vínculo entre virilidad y páramo castellano en sus famosos versos: “ ¡Castilla varonil, adusta tierra; I Castilla del desdén contra la suerte, I Castilla del dolor y de la guerra, I tierra inmortal, Castilla de la muerte!". 
te ser a la vez enérgico y suave, denso y flexible, dulce sin blandura y vigoroso sin dureza" (1935: 20). Y unas páginas más adelante:

El acento castellano en sus rasgos esenciales, depurados y refinados a través de largas generaciones, puede ser considerado como el elemento tradicional más antiguo de nuestra lengua, anterior probablemente a la existencia del mismo romance castellano, eco milenario del modo de hablar de todas las gentes que nos han precedido en esta tierra en que hemos venido al mundo y en que se mueve nuestra vida. (Navarro Tomás, 1935: 46)

Como se ha podido apreciar, en algunas de las citas que hemos reproducido las valoraciones que destacan el carácter varonil del castellano se alternan con otras de signo opuesto: así, se destaca la dulzura (pero sin blandura) y la (moderada) suavidad. De hecho, como advierte Terracini,

Por otro lado, no hay que olvidar otro valor que, aparentemente negado en España en las apreciaciones éticas, aparece con frecuencia en las valoraciones formales como calidad positiva: la dulzura misma. [...]. Las dos palabras-clave 'gravedad', 'dulzura', funcionan en simbiosis en varios campos: de la pronunciación, de la entonación, de las elecciones léxicas, hasta el de la caracterización de los estilos. (1992: 66)

Lo que importa subrayar es que "[f]rente a las otras lenguas la lengua española, en la polaridad axiológica dulce-grave, resulta fijada en el polo de lo grave, majestuoso, rico, abundante, más que en el polo de lo dulce, aun sin olvidar la existencia de éste [...]" (Terracini, 1992: 67).

Una vez llevado a cabo este somero recorrido histórico, cabe preguntarse a qué se debe esta percepción del castellano como lengua marcial y varonil, que acabó repitiéndose de pluma en pluma hasta convertirse en tópico. ¿Qué características fonéticas podríamos considerar relevantes como para fraguar semejante concep- 
ción? En el apartado siguiente, además del carácter varonil del castellano, tomaremos en consideración también otros rasgos afines y analizaremos las características fonéticas que los ponen de manifiesto.

\section{El carácter varonil del castellano y sus motivaciones fonéticas}

\subsection{El nivel segmental}

Al comentar el epigrama de Marcial que expusimos al principio, Moreno Soldevila (2006: 392) señala que la repetición de los fonos vibrantes en los versos 9-10 ("nostrae nomina duriora terrae I grato non pudeat referre versu") representa precisamente "a sonic symbol of the nomina duriora" [un símbolo sonoro de los nomina duriora], que el poeta bilbilitano aprovecha como expediente fonosimbólico, gracias a la aliteración, con el fin de evocar la dureza y asperidad del latín hispánico. El legado que dejarían los antiguos naturales de la Celtiberia en el genio de la lengua castellana vería en la expresividad de estas articulaciones de alto valor fonosimbólico su más patente efecto: es decir, los elementos segmentales más caracterizadores de su varonilidad serían precisamente las consonantes vibrantes, especialmente la múltiple. De hecho, se trata del único indicio concreto que es posible inferir de las fuentes antiguas. Si bien no aparecen referencias explícitas - la única es la que aparece en la definición de la letra $r$ en Covarrubias (2006 [1611]) (véase más adelante)—, corrobora nuestra hipótesis la supervivencia de ciertas estructuras y elementos (rechazo de $r$ - inicial, sufijación en -rr-, préstamos léxicos) claramente atribuibles a las lenguas prerromanas (especialmente al vasco), cuyo elemento característico y recurrente es /r/, como veremos a continuación.

Por otra parte, las metáforas sinestésicas que remiten a la imagen de un golpe o al sonido producido por la percusión de un tambor, como las que encontramos en la cita de Feijoo (1778 [1726]) ("La lengua Francesa (digámoslo así) se desliza: la Española golpea") o en el Poema de Almería ("illorum lingua resonat quasi tym- 
pano tuba"), bien pueden aludir al mecanismo articulatorio típico de una consonante vibrante, y no es casual que esa misma metáfora siga empleándose incluso en las descripciones científicas modernas del modo de articulación vibrante, para indicar las oclusiones del ápice de la lengua contra los alvéolos. Sirvan de ejemplo las siguientes, relativas a la vibrante múltiple, obtenidas de conocidos manuales y tratados de fonética: "La fase de posición es prolongable y consiste en dos o más golpes rápidos entre el ápice y los alvéolos" (Canellada \& Kuhlmann Madsen, 1987: 38), "La diferencia más importante entre las dos vibrantes es que la simple se pronuncia con un solo golpe rápido [...] mientras que la múltiple consiste en varios golpes rápidos [...]" (Hualde, 2014: 181); algunos autores, además, emplean, para / $\mathrm{s} /$, la denominación percusiva en lugar de vibrante simple para marcar la sustancial diferencia que existe entre los gestos articulatorios de /r/ y / $/$ / $c f$. Massone, 1988; NGRAE, 2011: 245). ${ }^{12}$

Según la definición de Covarrubias (2006 [1611]), $r$ es una letra que ya desde épocas pasadas se denomina canina, pues se pronuncia con estridor, "como el perro cuando regaña" (2006 [1611]: 1391). Añade el lexicógrafo que "[1]a lengua española interpone muchas veces esta letra en las dicciones, con que las hace sonar fuertes, sin que sea radical ni les pertenezca. Toparás en este libro muchos ejemplos adonde se advierte" (2006 [1611]: 1391). Uno de dichos ejemplos es el representado por la definición de broca, donde leemos: "El castellano interpone muy de ordinario la letra $r$ en los vocablos extranjeros de que usa, como en los propios suyos, con que hace su lengua más fuerte y varonil" (2006 [1611]: 357). Covarrubias establece, pues, una conexión patente entre el carácter varonil del castellano y la energía de este sonido que, por

12 También en otras lenguas se adopta la misma metáfora: por ejemplo, en inglés se emplea to tap 'dar un golpecito' ("In trill one flexible organ repeatedly taps against another" [En las vibrantes un órgano elástico golpea repetidamente contra otro] [Catford, 2001: 65]); tap es la denominación de la consonante vibrante simple (vs. trill). 
pertenecer tan hondamente al idioma, extendería su frecuencia incluso a las voces extranjeras (en este caso modificando el original boucle). ${ }^{13}$

En la estela de Covarrubias, el epíteto de letra canina acompañará a las definiciones de varios diccionarios posteriores que tomaron el repertorio como modelo, como los de Minsheu (1617) y Stevens (1706). También la Real Academia la incorpora como subentrada de la voz letra a partir de la edición de 1803 hasta la última (2014).

La honda raigambre de la vinculación de este sonido con el genio del idioma castellano permanece inalterada hasta nuestros días, como observamos en las reflexiones del periodista y escritor Álex Grijelmo: "Las erres se perciben a su vez con la connotación de la energía o de la fuerza [...] La $r$ que entra raspando en los oídos y que servirá para dotar de brío a las ideas aunque su contenido careciere de fuerza" (2000: 45-46). Y más adelante añade:

Nos seduce todo lo que procede de nuestros antepasados y, cómo no, lo que resistió en las palabras prerromanas que superaron los filtros y las invasiones. Páramo, barraca, barro, charco, galápago, rebeco, berro, berrueco... Nadie conoce el origen de estos vocablos, que existen desde que nuestra especie guarda memoria. Son palabras antiguas, mucho más viejas y calientes que un mueble del siglo XIII por el que pagarían cientos de millones. (2000: 268-269)

${ }^{13}$ En opinión de algunos autores, si el efecto de virilidad y fuerza está asegurado, las secuencias de consonante (tautosilábica) $+r$ introducirían un matiz de aspereza que sería ajeno a la lengua castellana y constituirían, por tanto, un elemento de dificultad en la pronunciación. Ello explicaría, según Jerónimo de San José (1651: 62-63), la epéntesis vocálica que aparece en palabras como corónica: "Llamase tambien Cronica; i nuestra lengua Española (que no sufre aspereza, ni dificultad en la pronunciación, i sonido de las palabras; i por eso añade ò quita letras a las dicciones asperas), pareciendoselo a esta, le añade una, ò en la primera silaba, diciendo, Coronica [...]". 
Posteriormente, vuelve Grijelmo a exponer el mismo concepto en El genio del idioma:

Tal vez entronque con el lenguaje de las cavernas la fuerza de esas erres que nos desahogan los enfados ('cabreo', 'bronca', 'cabrón') y que tanto gustan a los locutores deportivos por el vigor que transmiten: 'recorte', 'regate', 'remate', 'arrebata', 'raso', 'rompe', 'roba'... O la sonoridad que notamos en las viejas y recias voces prerrománicas y que pronunciaremos aún durante muchos siglos más ('barro', 'cerro', 'barraca', 'rebeco', 'berrueco'....). (2004: 9-10) ${ }^{14}$

Las fuentes lexicográficas antiguas aplican la metáfora canina tanto al fonema /r/ (como en cara, tres, cortar) como a /r/ (como en rosa, honra, carro), aunque, en cuanto al primero, parece desprenderse que su capacidad de conferir fuerza a las palabras se manifiesta particularmente cuando va precedido de una consonante tautosilábica ( $c$. broca). Como quiera que sea, es cierto que el fonema vibrante múltiple es el que con mayor eficacia manifiesta ese carácter de virilidad y fuerza, en virtud de su alto valor fonosimbólico; lo que no es de extrañar si se consideran sus características articulatorias únicas: en primer lugar, el relativamente elevado número de oclusiones o interrupciones, ${ }^{15}$ característica que parece exclusiva

${ }^{14}$ Nótese que no todas las voces mencionadas son de origen prerromano (como cerro, probablemente del latín cirrus). Para una lectura crítica del concepto de genio del idioma en Grijelmo puede verse Sánchez Manzanares (2019), quien analiza las proposiciones historicistas y nacionalistas que fundamentan el pensamiento del periodista.

${ }^{15}$ El número de oclusiones o bien de fases de abertura y cierre ( $c f$. Blecua Falgueras, 2001; Martínez Celdrán \& Fernández Planas, 2007) varía dependiendo de los estudios y de factores contextuales y estilísticos. Por poner un ejemplo, Navarro Tomás (1999 [1932]: 122) establece que en posición inicial de sílaba acentuada /r/ tiene tres oclusiones (vibraciones), cuatro tras vocal acentuada, dos tras consonante heterosilábica; Quilis (1999: 336), por su parte, observa una media de tres; de la Mota (1992) obtiene tres o cinco fases en habla de laboratorio pero solo dos en habla espontánea; en este mismo estilo de habla, Blecua 
de la lengua española - compartida solo por sus dialectos históricos, además de por el catalán, el gallego y el vasco-, un "derroche vibrante" (Grijelmo, 2000: 47) que sin duda confiere a las articulaciones vibrantes múltiples esa fuerza y virilidad de que nos habla Covarrubias. Bien lo expresa Fónagy (1983: 96), quien afirma que "Un $r$ très fortement roulé confère à l'espagnol [...] un cachet de masculinité sans diminuer la souplesse". [Una $r$ muy vibrante confiere al español un toque de masculinidad sin reducir la elasticidad]. ${ }^{16}$ De hecho, si examinamos el asunto desde la perspectiva del inconsciente, la actividad muscular enérgica de la lengua durante la producción de /r/ y el mecanismo articulatorio involucrado pueden despertar la imagen de un sonido eréctil (definición propuesta por el psicólogo húngaro István Hollós). A nivel inconsciente, la identificación de la lengua con el pene:

s'explique par des analogies morphologiques et fonctionnelles. La langue dirige le flux d'air à travers des espaces humides vers l'ouverture buccale. La langue et le pénis sont les seules structures musculaires attachées à un seul os. La forme et la couleur de la langue renforcent l'analogie. Un trait commun essentiel, mis en évidence par Hollós, [...] est l'érectilité de la langue [...]. (Fónagy, 1983: 97) $)^{17}$

Falgueras (1999), por su parte, encuentra tres (hay que tener en cuenta que, en habla sobre todo espontánea, pueden darse otros tipos de realizaciones; además de los autores mencionados, $c f$. también Ortiz de Pinedo Sánchez, 2017).

${ }^{16}$ De hecho, a diferencia de lo que suele o puede ocurrir en otras lenguas, /r/ en español parece destacar por su notable estabilidad, tal como lo señala Lindau (1985: 161).

17 "Puede explicarse por analogías morfológicas y funcionales. La lengua dirige el flujo de aire a través de los espacios húmedos hacia la abertura bucal. La lengua y el pene son las únicas estructuras musculares unidas a un solo hueso. La forma y el color de la lengua refuerzan la analogía. Un rasgo común fundamental, destacado por Hollós, es la erectilidad de la lengua." 
La lengua española ha sabido aprovechar el especial poder evocativo del fonema vibrante múltiple: una huella tangible de ello la encontramos en las onomatopeyas, en la fraseología y en la poesía, donde el sonido se convierte en un eco completo del sentido (Jakobson, 1960: 373). El español puede beneficiarse, quizás con mayor eficacia con respecto a otras lenguas, de recursos retóricos como la aliteración, precisamente gracias al alto valor fonosimbólico del fonema, en sus múltiples posibilidades evocativas: desde la esfera de los sentimientos y las emociones hasta los ruidos o los sonidos del ambiente que nos rodea. Como bien lo expresa Iribarren Argaiz (2010: 58), /r/ "es una consonante continua de notable fuerza y expresividad, lo que explicaría su frecuente aprovechamiento fonosimbólico en la poética castellana. Tal capacidad expresiva puede muy bien estar relacionada con el esfuerzo articulatorio que exige su producción". ${ }^{18}$

Parece ser, esta, una propiedad inherente a las consonantes vibrantes apicales en general, como afirma Fónagy (1983: 96): “Le $r$ est associé $[. .$.$] au combat. 'Le r$ prend tout son relief lorsqu'il s'agit d'actions violentes et véhémentes (quandoque exponuntur res acerbae ac vehementes)', écrit Vossius, en citant des vers de Virgile et d'Horace" [La $r$ se asocia al combate. 'La $r$ adquiere

18 Las razones articulatorias que explican la dificultad intrínseca a la producción de una vibrante múltiple quedan sintetizadas por Blecua Falgueras (2001: 7):

para iniciar a mantener la vibración del ápice de la lengua es necesario un control muy preciso de los diferentes órganos que intervienen en el proceso, ya que un mínimo desajuste de la tensión requerida en cada punto implica que no se produzca dicha vibración [...] Además, en la articulación de este sonido no sólo actúa el ápice de la lengua, sino que también se forma una constricción postdorsovelofaríngea [...] Esta doble articulación requiere mucha precisión en el control de la lengua, puesto que supone la realización de dos movimientos simultáneos, uno de ellos vibratorio, en la zona anterior, y el otro de constricción, en la zona posterior. 
todo su relieve cuando se trata de acciones violentas y vehementes', escribe Vossius, citando versos de Virgilio y Horacio]. ${ }^{19}$

En La Dorotea, Lope de Vega Carpio ya había destacado, mediante las palabras de Julio, precisamente la presencia representativa de este fono en castellano: "Porque estas erres son muy significativas y sonoras en nuestra lengua, y de excelente boato, como sarria, angurria, tirria y otras semejantes" (1987 [1632]: 384-385).

En lo que concierne a las onomatopeyas, en efecto, el español cuenta con numerosas creaciones expresivas en las que prima el sonido rótico, como rifirrafe, ringorrango, y creaciones onomatopéyicas como ris-ras ('sonido del rasgueo'), rin ('sonido de un timbre'), rataplán (“U. para imitar el sonido del tambor”, según el DLE, 2014), ratatá ('sonido de una ametralladora'), retintín ('sonido de una campana'). Según el DLE también la voz cencerro sería una creación onomatopéyica. Entre las interjecciones se puede mencionar arre ('estímulo a las bestias' o 'expresión de rechazo', $D L E)$. Asimismo, la motivación de las unidades fraseológicas podría deberse a su vigorosa consistencia fónica: erre que (te) erre, estar erre y haches y erres. De las dos primeras nos deja constancia Gonzalo Correas en su Vocabulario de refranes y frases proverbiales (1967 [1627]: 634): "De akí sale tomar el nonbre 'erre'

19 De hecho, "La distribution de fréquence des phonèmes dans les poèmes appartenant à deux populations sémantiques différentes, dans les poèmes belliqueux d'une part, dans les poèmes idylliques d'autre part, reflète en effet une forte tendance à associer les $r$ à la violence" [La distribución de frecuencia de los fonemas en los poemas pertenecientes a dos poblaciones semánticas diferentes, en los poemas bélicos por una parte, en los poemas idílicos por otra, refleja en efecto una fuerte tendencia a asociar las $r$ con la violencia] (Fónagy, 1983: 96). Nótese que la consonante vibrante múltiple puede sugerir también imágenes dulces y plácidas, totalmente opuestas a las evocadas por los ejemplos mencionados: por ejemplo, el "deslizamiento suave y la cadencia duradera e indefinida del río" (González Martínez, 1991: 44), sugeridos por corriendo y rumor en los siguientes versos de la Fábula de Faetonte (Poema viII) de Francisco de Aldana (1985): "[...] dentro un umbroso seno, do corriendo I vio un luciente cristal que en todo el valle I dilataba el rumor que dél nacía [...]". 
solo a muchos propósitos, denotando firmeza, kostanzia i porfía afirmando o negando; kon exenplos se hará más klaro: 'Erre, erre, dize erre': dize 'no'. 'Io a llamarle, i él erre': el ke está en sus treze. 'Estoi erre todos los días en la lizión': asisto kon puntualidad. 'Fulano sienpre erre ke erre al ofizio', ke es: sin faltar de él día”.

Por lo que se refiere a erre que (te) erre, Iribarren (1995) apunta precisamente a la dificultad de pronunciar el sonido para explicar la plasmación de la locución, aunque Corriente (1999, s.v. herre que herre) ofrezca una explicación diferente y señale que la grafía con $h$ demuestra que no se trata del nombre de la letra y que, por consiguiente, la locución no se refiere a un sonido.

Con respecto a la tercera, se trata de una locución de la que empieza a haber constancia en los repertorios lexicográficos a partir del siglo XIX: "ENTRAR CON HACHES Y ERRES. f. Tener malas cartas el que va á ganar la mano, ó la polla. Stulte se tradere sorti in foliis lusoriis (RAE, 1803, s.v. entrar)". Pero volvamos sobre las huellas del genio del idioma: que la articulación vibrante múltiple, con su expresividad y fuerza, represente uno de los rasgos más inmutables de su personalidad es una hipótesis fascinante, refrendada por las teorías que defienden un papel activo de las lenguas prerromanas (en los aspectos que vamos a considerar enseguida, nos referiremos al vasco; véase la Nota 15) en la configuración de algunas características de la fonología (y la morfología) del castellano. Y no puede ser de otro modo, si consideramos que una gran cantidad de los primeros hablantes del castellano fue posiblemente vascohablante. De hecho, el fonema vibrante múltiple forma parte de las dieciséis consonantes básicas del vasco antiguo y medieval (Michelena, 1995 [1957]: 106); es más: a lo largo de su historia, la lengua vasca ha mostrado una tendencia cada vez mayor a neutralizar la oposición $/ \mathrm{r} / \sim / \mathrm{f} /$ a favor del vibrante múltiple en todas las posiciones, excepto entre vocales, donde hay contraste fonológico entre los dos fonemas ( $c f$. Trask, 1997: 144-146; Egurtzegi, 2013: 140-142). El fonema vibrante múltiple, pues, está profundamente arraigado en la lengua vasca y es uno de los rasgos más distintivos de su rostro sonoro. Pues bien, si por un lado, en 
español, el contraste en posición intervocálica entre /r/ y / / / tiene su origen en la oposición $/ \mathrm{r} / \sim / \mathrm{rr} /($ simple $\sim$ geminada) del latín, por el otro, no parece demostrable la ascendencia latina de /r/ en las otras posiciones, debido a la distinta distribución de las vibrantes en ambas lenguas: si para la típica realización múltiple de /r/ del español en posición inicial de palabra puede suponerse un cambio independiente, ${ }^{20}$ por otro lado, si también se asume que se debe al contacto vasco-castellano la restricción fonotáctica que rechaza ese fonema en dicha posición (en el castellano antiguo $)^{21}$ mediante el desarrollo de una vocal protética:

la generación de una vocal protética ante /r-/ múltiple inicial debe ser entendida como influjo de la lengua vasca sobre el romance castellano, pues no hay razones para atribuirla a hechos románicos; en textos castellanos antiguos encontramos también casos de Arredondo por Redondo, arroturas por roturas, etc.,

${ }^{20}$ Hualde (2014: 186) sugiere que este cambio se debe a un refuerzo de la consonante vibrante inicial de palabra, paralelo al que experimentaron /1-/ y /n-/ en otras lenguas iberorrománicas: $c f$. catalán y asturiano lluna /' Kuna/ 'luna', asturiano ñome /' nome/ 'nombre' (ejemplos del autor). Tampoco debe descartarse el origen vasco del fenómeno (refuerzo de la vibrante sin desarrollo de una vocal protética), como parece suponer Rohlfs (1970: 150), al evidenciar el paralelismo entre el gascón, de sustrato aquitano (esto es, protovasco), y el castellano con respecto al tratamiento de la vibrante inicial latina: " $D$ ' autre part nous trouvons quelque chose d'analogue en Espagne, où chaque $r$ à l'initiale se redouble. Bien qu'on écrive rana, rey, rueda, redondo, on prononce rrana, rrey, rrueda, rredondo" [Por otra parte encontramos algo parecido en España, donde toda $r$ inicial se dobla. Aunque se escribe rana, rey, rueda, redondo, se pronuncia rrana, rrey, rrueda, rredondo]. Rohlfs, sin embargo, parece desconocer los ejemplos con prótesis vocálica mencionados por Echenique Elizondo en la cita que reproducimos. También se podría aventurar que la realización múltiple fue ocasionada por una vocal protética originaria para posteriormente quedar descubierta a raíz de la eliminación de esa misma vocal.

${ }^{21}$ En el español actual solo quedan pocos rastros de este proceso, como arruga, arrepentirse, etc. 
que, sin duda, están mostrando la influencia del adstrato vasco en su configuración. (Echenique Elizondo, 2004: 73)

Por el contrario, existen buenas razones para defender la idea del origen $\operatorname{vasco}^{22}$ de un gran número de préstamos en - $\operatorname{Vrr}(a)$, que, como sostiene Iribarren Argaiz (2010: 1), "una vez asimilados al castellano, pasan a modelar otros muchos términos romances derivados, produciéndose así una rica sufijación romance en - $\mathrm{Vrr} \mathrm{V}^{\prime}$. La autora identifica 279 préstamos, sobre un total de 579 palabras en - $r r V$, las cuales "se refieren a un área de uso que comprende Asturias, Vascongadas, Navarra, Aragón, La Rioja, Castilla, La Mancha, Andalucía, Extremadura, Baleares y Canarias" (Iribarren Argaiz, 2010: 32). A modo de ejemplo, considérense los siguientes vocablos de uso general, todos ellos préstamos directos del vasco: pizarra, chatarra, chaparro, guarro, modorra y muchísimos más; en cuanto a los derivados romances, los sufijos en - VrrV o - VrriV suelen tener valor diminutivo (también aumentativo, como en el caso de -orrV) y/o despectivo: $c f$. -arra (tunarra), ${ }^{23}$-arro/-arra (mocarro), -arria (bambarria), -arrio (angarrio 'persona o animal

${ }^{22}$ El vasco fue lengua de adstrato en los territorios en los cuales se fraguó el castellano. Tradicionalmente, a fenómenos como el que aquí se ilustra, solía atribuirse un genérico sustrato mediterráneo ( $c f$. Menéndez Pidal \& Tovar, 1958) o bien un origen ibérico, etiqueta, esta última, que "presuponía cierto parentesco entre vasco e ibérico" (Iribarren Argaiz, 2010: 8). Como aclaran Echenique Elizondo y Martínez Alcalde (2013: 47-48), "En el caso de que se quiera seguir defendiendo la filiación vasco-ibérica (cuestión no totalmente resuelta todavía hoy, si bien hay un cierto consenso en aceptar que no hay parentesco genético sino mera relación cultural entre ambos), se entendería como territorio lingüísticamente ibérico tan solo el mediterráneo con cierta penetración hacia el interior por el sur [...]". Con todo, se reconoce la existencia de coincidencias tipológicas entre el vasco y el ibérico, entre ellas, el rechazo de la consonante vibrante en posición inicial (Echenique Elizondo, 2004: 73).

${ }^{23}$ Separamos -arra del siguiente sufijo (-arro/-arra, donde - $a$ es marcador de género, así como en los pares de sufijos que siguen), porque "-arr(a) aplicado a adjetivos produce en un primer momento adjetivos epicenos, de acuerdo a los modelos de los préstamos vascos" (Iribarren Argaiz, 2010: 74). 
muy flaco', utilizada en Colombia y Venezuela), -orro/-orra (aceitorro, vidorra), -orrio/-orria (villorrio, vidorria 'vida arrastrada y triste', utilizada en Argentina, Colombia y Venezuela), -urro/-urra (baturro), -urrio/-urria (bajurrio). Como concluye la autora al respecto:

Se puede sostener, por tanto, la coherencia de la sufijación en -rr- con los hábitos lingüísticos de los primeros hablantes de castellano, entre los que posiblemente se dió una alta proporción de hablantes de euskera. Estos vasco-hablantes o hablantes bilingües inmersos en un mundo románico, tenderán a utilizar numerosas palabras en $-r$ que, siendo vibrante múltiple [R], seguidas por una vocal terminarán en secuencias - $V r r V$ que irán afianzándose en la lengua neolatina. (Iribarren Argaiz, 2010: 39)

Como se ve, si consideramos su frecuente valor despectivo, los sufijos en -rr- no hacen sino confirmar el carácter fundamental de lo castellano, polarizándolo, en este caso, en la vertiente más agresiva de la varonilidad, donde la vibrante múltiple expresa de manera emblemática la actitud despectiva del hablante hacia la idea vehiculada por la raíz: sonido duro, áspero y difícil, que bien supo aprovechar Marcial en sus versos.

En contraste, el genio de la lengua castellana también sabe mostrar su cara más noble; por decirlo con palabras de Correas (1954 [1625]: 494), "más grave, llena, dulze, i bien sonora, clara, distinta [...]"; recordemos también las palabras, ya citadas, del padre Fita, que define el acento castellano "claro, fijo y majestuoso", y de los otros autores mencionados, que comparten las mismas valoraciones. ${ }^{24}$ Sin duda, en ello tienen, de nuevo, un papel importante

${ }^{24}$ Navarro Tomás (1935: 14, 17-18), en su discurso de ingreso en la Academia de la Lengua Española, resume estas cualidades de la siguiente manera: "Sobre el español [...] han expresado asimismo opiniones coincidentes las gentes más diversas [...]. Coinciden la mayor parte de las manifestaciones de estos autores 
las consonantes vibrantes, cuya dureza "est d'abord liée à l'idée de grandeur et de majesté" [está ante todo relacionada con la idea de grandeza y majestad] (Fónagy, 1983: 96); sin embargo, es opinión compartida que son sobre todo las vocales, con su timbre claro y nítido, las que favorecen, merced también a su alta frecuencia, ${ }^{25}$ la percepción del castellano como lengua dotada de gran sonoridad y majestuosidad ( $c f$. Navarro Tomás, 1935: 18). El timbre estable de las vocales y su duración constante, así como la preferencia por las vocales periféricas, pueden considerarse, asimismo, una consecuencia de la tensión articulatoria del español. Una vez más, una clara manifestación del genio del idioma, inmutable a lo largo de los siglos: como es sabido y unánimemente aceptado, el vocalismo del español, con su simplicidad — solo cinco fonemas vocálicos y tres grados de abertura, tanto para la posición acentuada como para la inacentuada-, tiene su origen en la lengua vasca, con la cual el latín estuvo en contacto, precisamente, en las zonas de origen del castellano (Echenique Elizondo, 2004: 71-72).

\subsection{El nivel suprasegmental y los ajustes articulatorios}

Más allá de las características propiamente segmentales, no se puede descartar la hipótesis de que características relacionadas, por un lado, con lo suprasegmental y, por otro, con ciertos ajustes articulatorios a medio y largo plazo, tuvieran un papel relevante en reforzar la percepción de varonilidad y fuerza —en sus dos vertientes, tanto la más ruda como la más noble-, sobre todo si consideramos que son aspectos que confieren una cualidad fonética general a las lenguas (Gil Fernández, 2007: 192). ${ }^{26}$ Por lo que se

en señalar en el acento español tres rasgos principales: sonoridad, aire varonil y tono de dignidad". Para un análisis crítico del discurso de Navarro Tomás, remitimos a Poch Olivé (2018).

${ }^{25}$ Se pueden consultar datos estadísticos en Arias Rodríguez (2016) y en Gil Fernández (2007: 219, Nota 46).

${ }^{26}$ En palabras de Abercrombie (1967: 91), se trata de aquellas características "which are present more or less all the time that a person is talking: it is a 
refiere a las primeras, y en opinión de Navarro Tomás, al carácter varonil contribuirían las características del acento prosódico: "La impresión de fortaleza del acento castellano procede sin duda del relativo volumen y relieve que en nuestra lengua tiene el acento de intensidad" (1935: 21), en tanto que el tono de dignidad, y quizás de marcialidad, residiría en la entonación:

La entonación castellana no se compone de escalas, arpegios ni ligaduras, sino de notas prolongadas, relativamente uniformes, acordadas entre sí por intervalos regulares. El orden y compás de estos movimientos y la pureza y sobriedad de estas líneas dan al acento castellano su pausada armonía y su señoril distinción. Se comprende que tales cualidades, unidas al señalado relieve de la intensidad espiratoria, hayan hecho apreciar en el acento español cierto aire marcial. (1935: 26).

Ahora bien, es nuestra intención centrarnos sobre todo en los ajustes articulatorios. Nos referimos a la tensión articulatoria, a algunos ajustes supralaríngeos y a cierto tipo de actividad laríngea - aunque referida, esta última, a un grupo social particular, como veremos a continuación.

En lo que concierne a la tensión articulatoria, de la que dependería la impresión perceptiva de la pronunciación 'clara', 'limpia', 'nítida' de los castellanohablantes (Gil Fernández, 2007: 214),

quasi-permanent quality running through all the sound that issues from his mouth" ("que están presentes más o menos todo el tiempo que una persona está hablando: es una cualidad casi permanente que recorre todo el sonido que sale de su boca"). En la clasificación de Laver (1980), los ajustes articulatorios (articulatory settings) pueden ser no localizados (ya que afectan a todo el tracto vocal: tensión articulatoria) o localizados (vinculados a una zona específica del tracto vocal); los localizados, a su vez, abarcan los ajustes de la laringe (los tipos de fonación) y los ajustes supralaríngeos (modificaciones longitudinales, modificaciones latitudinales y ajustes velofaríngeos). 
existe acuerdo en que los músculos del aparato vocal, en la articulación castellana, se mantienen relativamente contraídos, en tanto que el gasto de energía por unidad de tiempo es mayor (hablando siempre con respecto al modelo neutro). Asimismo, no se discute que este hecho afecta a todos los restantes ajustes articulatorios [...] Es muy probable que esta relativa tensión del español lleve emparejado un volumen más alto en las emisiones [...] Todo esto explicaría la impresión que muchos extranjeros manifiestan sobre la 'fortaleza' del acento castellano. (Gil Fernández, 2007: 215)

A la tensión articulatoria se pueden atribuir varios rasgos que se han señalado para el español, entre ellos, la tendencia a la sílaba abierta y a la isocronía silábica. Estas características, junto a la notable estabilidad de los sonidos del español — no solo de los vocálicos, sino de los consonánticos, especialmente en las variedades más conservadoras-, así como "la mayor rapidez en los movimientos y el menor tiempo empleado en pasar de un cambio rápido a una relativa nivelación" (Gil Fernández, 2007: 216), son propiedades inherentes y sobre ellas se sustentan, con mucha plausibilidad, todas aquellas valoraciones que destacan la fuerza y la energía, esto es, la varonilidad de esta lengua, y no solo eso, también "aquella medida económica de consonantes y vocales" de que nos habla el ya citado de Vargas Ponce (1793) y la flexibilidad y armonía (de Iriarte, 1779) de una lengua que no tiene nada de "tropiezos, ni vazios, i corre más bien sonora i grave" (Correas, 1954 [1625]: 491).

En cuanto a los ajustes supralaríngeos comentamos uno de tipo latitudinal, esto es, que afecta a la anchura del tracto vocal, y no a la longitud: la disposición de la masa lingual, de la que dependen las bases articulatorias de las lenguas — que pueden ser de tendencia más o menos anterior o más o menos posterior con respecto a la disposición neutra ( $c f r$. Laver, 1980). Nos parece reveladora, a este respecto, la descripción que hace Navarro Tomás (1933: 275) de la base del castellano, que, en comparación con el andaluz, pre- 
sentaría resonancias graves e interiores (más viriles, nos atrevemos a añadir desde nuestra perspectiva):

La base articulatoria de la pronunciación de Castilla tiene por centro o eje una zona de la boca algo más interior que la de la pronunciación andaluza [...] Las vocales $o, u$ son más cerradas y velares en castellano que en andaluz, y en determinadas circunstancias ejercen en ciertas partes de Castilla una influencia metafónica sobre la vocal precedente de que apenas hay indicios en el habla andaluza [...] La velarización de la $a$ posterior y de la $l$ cóncava y la fricación de la $j$ son más fuertes y marcadas $^{27}$ en Castilla que en Andalucía. En el efecto de conjunto del acento regional, la pronunciación castellana presenta, en suma, resonancias graves e interiores claramente distintas del timbre relativamente agudo y palatal que caracteriza al andaluz.

En relación con la actividad laríngea, nos referimos a un tipo particular de fonación que Armstrong, Henriksen y DiCanio (2015) observan - alternando con la modal (neutra) — en hablantes peninsulares jóvenes de sexo femenino (en algunas más que en otras) y que analizan acústicamente en una muestra de mujeres manchegas. Se trata de la voz áspera, ${ }^{28}$ que se caracteriza, según Laver (1979), por una hipertensión laríngea que produce una excesiva aproximación de los pliegues vocales, con presencia de una tensión de

${ }^{27}$ De hecho, en pronunciación enérgica, / $\mathrm{x}$ / se realiza típicamente como fricativa vibrante.

${ }^{28}$ Como afirma Poyatos (1994: 62), la etiqueta de voz áspera "abarca en realidad varias formas de ruido laríngeo y hablamos a veces un tanto indistintamente de voz 'ronca' ('hoarse' y, más literaria, 'raucous', rauca), 'recia', 'pastosa', 'dura', 'seca', 'rasposa' ('coarse', 'rasp')'. Concretamente, la voz de los sujetos femeninos estudiados por Armstrong, Henriksen y DiCanio (2015) es calificable como hoarse. Remitimos al artículo para los detalles técnicos y metodológicos. 
aducción extrema y una compresión media (en la literatura médica se habla de disfonía).

Lo que cabe destacar, más allá de los aspectos fisiológicos, es que los ajustes de la laringe, como el que se describe aquí, a la par de los demás ajustes articulatorios a largo plazo, suelen tener significación social y acarrear información sobre la etnicidad de los hablantes o caracterizar a ciertos grupos sociales dentro de un mismo idioma; para el español, los escasos estudios que se han llevado a cabo hasta la fecha sugieren, además, la posibilidad de que existan diferencias de sexo (Trittin \& de Santos y Lleó, 1995; Mendoza, Valencia, Muñoz \& Trujillo, 1996). Incluso, al menos por lo que a la hoarse voice se refiere, los hablantes nativos parecen ser conscientes de esas diferencias y propensos a desarrollar estereotipos sociales al respecto (Armstrong, Henriksen \& DiCanio, 2015: 296). El test perceptivo llevado a cabo por los tres investigadores en el marco de su estudio revela que de los cuatro adjetivos más frecuentemente utilizados por los 50 participantes en el test (femenina, pasota, inteligente, fuerte) los que con mayor frecuencia se asocian a la hoarse voice son pasota y fuerte, en tanto que las hablantes que no presentan esa característica (modal voice) se clasifican más frecuentemente mediante los adjetivos femenina e inteligente. Otros adjetivos menos utilizados apuntan a lo mismo: además de expresiones como 'no muy inteligente' y 'no muy femenina' (incluso, uno de los participantes en el test clasifica erróneamente como hablante de sexo masculino a una de las mujeres de la muestra), aparecen barriobajera, bruta, choni, dicharachera, lista de calle, simplona (vs. agradable, cursi, dulce, sincera, responsable, maja, noble). En cuanto al origen de cada grupo definido de acuerdo con el tipo de voz, la mayoría de las hablantes evaluadas como rurales ('pueblo', 'zona rural' vs. 'zona urbana') pertenece al grupo de los sujetos con hoarse voice.

No deja lugar a dudas la similitud entre la antiguas apreciaciones -latinas: cfr. "duriora" / "rustica" / "crassiora" [nomina], "fortius loquetur" [nobis filia] (Martialis, 1969) o castellanas: cfr. "dureza, i dificultad" ["destos nombres"] (de Aldrete, 2002 
[1606]), "difícil y áspera" [de pronunciar, con referencia a "la lengua antigua española"] / "varonil" [lengua] (Covarrubias, 2006 [1611])—, ya sea que se apliquen a los topónimos prerromanos o a las peculiaridades fonéticas del latín hispánico o bien al propio castellano, y las proporcionadas por hablantes nativos contemporáneos, y no deja de sorprender la evidente coincidencia de ciertas apreciaciones.

Sin pretender con ello afirmar una continuidad entre las lenguas de sustrato habladas en la península ibérica prerromana, el latín hispánico y el castellano en relación con la actividad laríngea — tarea imposible de realizar, por razones obvias_-, resulta sin embargo interesante la presencia — ¿persistencia? ¿apariciones y desapariciones de un genio caprichoso a lo largo de la historia?-, en hablantes femeninas de castellano (¿cómo no ceder a la tentación de pensar en la hija de Marcial, que "fortius loquetur"?), de características relacionadas con un tipo particular de fonación que encajan perfectamente, empezando por la propia denominación técnica del ajuste que nos ocupa (voz áspera), con los juicios impresionistas que emergen de las atestiguaciones antiguas y con el mencionado tópico áureo del carácter varonil de la lengua castellana.

\section{Conclusión}

A raíz de lo comentado hasta ahora, somos conscientes de que abordar el tema del genio de la lengua —o, según una perspectiva humboldtiana, la evidencia de una energeia, es decir, una emanación espontánea del espíritu ${ }^{29}$ — no es siempre fácil, seguramente por cierto riesgo de inconsistencia o de debilidad de las hipótesis, que a veces podrían carecer de fundamento en datos ciertos. Sin embargo, el magisterio de Ramón Menéndez Pidal nos muestra que, a menudo, incluso la observación más atenta de los datos esconde una propensión hacia lo espiritual, como pudo resumir

${ }^{29}$ Nos referimos a la clásica oposición ergon/ energeia propuesta por von Humboldt (1836: 41). 
García Isasti (2004: 405): "bajo los razonamientos cientifistas de nuestro autor, en último término, fuerzas misteriosas y atávicas guían la evolución del idioma".

Ante este reparo, el propósito de nuestro trabajo ha sido más bien el de proponer algunas reflexiones sobre testimonios antiguos de la que, en términos sociolingüísticos, se denominaría actitud afectiva: frente a la dificultad (o imposibilidad) de establecer con rigor científico en qué rasgos estriba el carácter varonil del castellano - rudo y tosco, pero también grave, majestuoso, sonoro-, lo cierto es que la larga historia de las ideas lingüísticas nos deja constancia de un hecho incuestionable, esto es, la existencia de una actitud compartida, tanto en el espacio (dentro y fuera de España) como en el tiempo (a lo largo de los siglos), hacia dicha lengua, actitud que se manifiesta mediante una adjetivación recurrente. Y no es solo cuestión de tópicos: los tests perceptivos realizados en investigaciones sociolingüísticas actuales van en el mismo sentido. La percepción del castellano como lengua varonil, pues, no solo es algo evidente, sino que en ocasiones parece posible aislar algunos de los elementos en que se fundamenta: rasgos concretos y perfectamente observables. Claro está: ello no significa que haya una relación necesaria entre la actitud y el rasgo lingüístico; lo innegable, sin embargo, es que la existencia de la primera, al igual que la naturaleza del segundo, es un hecho objetivo, si bien, por supuesto, en su esencia no lo es (pues se trata de algo que atañe a la esfera de la afectividad). La mayoría de los rasgos fonéticos que comentamos en este trabajo - tanto los segmentales y suprasegmentales como los que tienen que ver con los ajustes articulatorios- han sido seleccionados a partir de la relación que es posible establecer entre las distintas cualidades atribuidas a la lengua por los antiguos autores y específicos rasgos objetivos de naturaleza fonética, propios del castellano. Trazamos estas relaciones por vía hipotética - valiéndonos, frecuentemente, de las intuiciones del maestro de la fonética española, Tomás Navarro Tomás-, puesto que solo en muy contados casos las fuentes antiguas nos ofrecen referencias explícitas a elementos fonéticos concretos (como es el caso de la 
consonante vibrante): al fin y al cabo, la lengua sigue guardando "el secreto de su entraña fonética" (Navarro Tomás, 1935: 12).

\section{Referencias}

Abercrombie, David (1967). Elements of general phonetics. Edimburgo: Edinburgh University Press.

Alfayé Villa, Silvia (2013). Marcial y la construcción del estereotipo del "macho celtibérico”. En Francisco Marco Simón, Gabriel Sopeña Genzor y Francisco Pina Polo (Coords.), Aragón antiguo: fuentes para su estudio (pp. 52-60). Zaragoza: Universidad de Zaragoza.

Arias Rodríguez, Iván (2016). Cálculo de frecuencias de aparición de fonemas y alófonos en español actual utilizando un transcriptor automático. Loquens, 3(1), 1-29. http://dx.doi.org/10.3989/loquens.2016.029 Armstrong, Meghan E.; Henriksen, Nicholas, \& DiCanio, Christian (2015). Sociophonetic analysis of young Peninsular Spanish women's voice quality. En Rachel Klassen, Juana M. Liceras \& Elena Valenzuela (Eds.), Hispanic linguistics at the crossroads: Theoretical linguistics, language acquisition and language contact (pp. 293-312). Ámsterdam: John Benjamins.

Binotti, Lucia (1995). La teoría del 'castellano primitivo': nacionalismo y reflexión lingüística en el Renacimiento español. Münster: Nodus Publikationen.

Blecua Falgueras, Beatriz (1999). Características acústicas de la vibrante múltiple del español en habla espontánea. En Eugenio Martínez Celdrán, Silvia Planas Morales y Joaquín Romero Gallego (Eds.), Actas del I Congreso de Fonética Experimental (pp. 119-126). Tarragona: Universitat Rovira i Virgili/Universitat de Barcelona.

Blecua Falgueras, Beatriz (2001). Las vibrantes del español: manifestaciones acústicas y procesos fonéticos (Tesis doctoral inédita). Universidad Autónoma de Barcelona, Barcelona. https://www.tdx.cat/hand le/10803/4859\#page $=1$

Cafford, John Cunnison (2001). A practical introduction to phonetics (2a. ed.). Oxford: Oxford University Press. 
Canellada, María Josefa, \& Kuhlmann Madsen, John (1987). Pronunciación del español: lengua hablada y literaria. Madrid: Castalia.

Castelar, Emilio (1880). Discursos leídos ante la Real Academia Española en la recepción pública del Sr. D. Emilio Castelar el día 25 de abril de 1880. Madrid: Imprenta de J. García a cargo de J. Peña.

Citroni, Mario (2002). L'immagine della Spagna e l'autorappresentazione del poeta negli epigrammi di Marziale. En Gianpaolo Urso (Ed.), Hispania terris omnibus felicior: Premesse ed esiti di un processo di integrazione (pp. 281-302). Pisa: Edizioni ETs.

Correa Rodríguez, José Antonio (2002). La distribución de las oclusivas orales en la toponimia prerromana de la Bética. Palaeohispánica, 2, 133-139. Correas, Gonzalo (1954 [1625]). Arte de la lengua española castellana. Madrid:

Consejo Superior de Investigaciones Científicas.

Correas, Gonzalo (1967 [1627]). Vocabulario de refranes y frases proverbiales.

Burdeos: Institut d'Études Ibériques et Ibéro-Américaines de l'Université de Bordeaux.

Corriente, Federico (1999). Diccionario de arabismos y voces afines en iberorromance (2a. ed. ampliada). Madrid: Gredos.

de Aldana, Francisco (1985). Poesías castellanas completas. Madrid: Cátedra. de Aldrete, Bernardo (2002 [1606]). Del origen y principio de la lengua castellana o romance que se usa en España. Valladolid: Maxtor.

de Covarubias Orozco, Sebastián (2006 [1611]). Tesoro de la lengua castellana o española. Madrid: Iberoamericana Vervuert.

de Henao, Gabriel (1689). Averiguaciones de las antiguedades de Cantabria.

Salamanca: por Eugenio Antonio García.

de lriarte, Tomás (1779). La música: poema. Madrid: Imprenta Real de la Gazeta.

de la Mota, Carme (1992). Caracterización acústica de los sonidos vibrantes del español en distintos estilos de habla. Revista Española de Lingüística, 22(1), 220-221.

de San José, Jerónimo (1651). Genio de la historia por el P. F. Geronimo de S. Joseph Carmelita Descalzo. Zaragoza: Imprenta de Diego Dormer. https://books.google.it/books?id=4jb9EdI7us4C\&printsec=frontco ver\&hl=it\&source $=\mathrm{gbs} \_g e \_s u m m a r y \_r \& c a d=0 \# \mathrm{v}=$ onepage $\& \mathrm{q} \&$ $\mathrm{f}=$ false 
de San Pedro, Benito (1769). Arte del romance castellano dispuesta segun sus principios generales i el uso de los mejores autores. Valencia: Benito Monfort.

de Unamuno, Miguel (1966). Obras completas de don Miguel de Unamuno. Madrid: Escelicer.

de Vargas Ponce, José (1793). Disertación acerca del castellano. En Declamación contra los abusos introducidos en el castellano presentada y no premiada en la Academia Española año de 1791: siguela una Disertacion sobre la lengua castellana, y la antecede un diálogo que explica el designio de la obra. Madrid: en la imprenta de la viuda de Ibarra. de Vega Carpio, Lope (1987 [1632]). La Dorotea. Edición de Edwin S. Morby. Madrid: Castalia.

$D L E=$ Real Academia Española (2014). Diccionario de la Lengua Española (23a. ed.). https://dle.rae.es/?w=diccionario.

Echenique Elizondo, María Teresa (2004). La lengua vasca en la historia lingüística hispánica. En Rafael Cano (Ed.), Historia de la lengua española (pp. 59-80). Barcelona: Ariel.

Echenique Elizondo, María Teresa, \& Martínez Alcalde, María José (2013). Diacronía y gramática histórica de la lengua española (5a. ed.). Valencia: Tirant lo Blanch.

Egurtzegi, Ander (2013). Phonetics and Phonology. En Mikel Martinez-Areta (Ed.), Basque and Proto-Basque: language-internal and typological approaches to linguistic reconstruction (pp. 119-172). Fráncfort: Peter Lang.

Feïjo, Benito Jerónimo (1778 [1726]). Paralelo de las Lenguas Castellana, y Francesa. En Teatro crítico universal (tomo primero, discurso xv, §17). Fita y Colomé, Fidel (1879). Discursos leídos ante la Real Academia de la Historia en la recepción pública del R. P. Fidel Fita y Colomé (2a. ed.). Madrid: Imprenta de Maroto e hijos.

Fónagy, Ivan (1983). La vive voix: essais de psycho-phonétique. París: Payot. Galmés de Fuentes, Álvaro (2000). Los topónimos: sus blasones y trofeos (la toponimia mítica). Madrid: Real Academia de la Historia.

García Isasti, Prudencio (2004). La España metafísica: lectura crítica del pensamiento de Ramón Menéndez Pidal (1891-1936). Bilbao: Euskaltzaindia. 
Gil, Juan (2004). Marcial en España. Humanitas, 56, 225-326.

Gil Fernández, Juana (2007). Fonética para profesores de español: de la teoría a la práctica. Madrid: Arco Libros.

Giner de los Ríos, Francisco (2004 [1886]). Paisaje. En Obras selectas (pp. 792-

801). Edición de Isabel Pérez-Villanueva Tovar. Madrid: Espasa

Calpe.

González Martínez, Dolores (1991). Fonosimbolismo y aliteración: Francisco de

Aldana frente a la palabra poética. Scriptura, 6-7, 41-50.

Grijelmo, Álex (2000). La seducción de las palabras. Madrid: Taurus.

Grijelmo, Álex (2004). El genio del idioma. Madrid: Taurus.

Hualde, José lgnacio (2014). Los sonidos del español. Cambridge: Cambridge

University Press.

lribarren Argaiz, Mary C. (2010). Influencias vascas en la sufijación castellana: morfología y contacto de lenguas. Anuario del Seminario de Filología Vasca Julio de Urquijo. International Journal of Basque Linguistics and Philology, 44(1), 1-283.

Iribarren, José María (1995). El porqué de los dichos: sentido, origen y anécdota de los dichos, modismos y frases proverbiales de España con otras muchas curiosidades. Pamplona: Gobierno de Navarra.

Jakobson, Roman (1960). Closing Statement: Linguistics and Poetics. En Thomas Sebeok (Ed.), Style in Language (pp. 350-377). Cambridge: Massachusetts Institute of Technology Press.

Laver, John (1979). The description of voice quality in general phonetic theory. En Edinburgh University Department of Linguistics Work in Progress, 12, pp. 30-52.

Laver, John (1980). The phonetic description of voice Quality. Cambridge:

Cambridge University Press.

Lindau, Mona (1985). The story of /r/. En Victoria A. Fromkin (Ed.), Phonetic

Linguistics: Essays in honor of Peter Ladefoged (pp. 157-168). Orlando: Academic Press.

Machado, Antonio (1991 [1917]). Orillas del Duero. En Campos de Castilla (1907-1917). Madrid: Cátedra.

Martialis = M. Val. Martialis epigrammata (1969). Edición de Watson M. Lindsay.

Oxford: Oxford University Press.

Martínez Celdrán, Eugenio, \& Fernández Planas, Ana María (2007). Manual de fonética española. Barcelona: Ariel. 
Massone, María lgnacia (1988). Estudio acústico y perceptivo de las consonantes nasales y líquidas del español. Estudios de Fonética Experimental, 3, 13-34.

Menéndez Pidal, Ramón, \& Tovar, Antonio (1958). Los sufijos con -rr- en España y fuera de ella, especialmente en la toponimia. Boletín Real Academia Española, 38, 161-214.

Mendoza, Elvira; Valencia, Nieves; Muñoz, Juana, \& Trüillo, Humberto (1996). Differences in voice quality between men and women. Use of the long-term average spectrum (LTAS). Journal of Voice, 10(1), 59-66.

Michelena, Luis (1995 [1957]). The Ancient Basque Consonants. En José I. Hualde, Joseba A. Lakarra \& Robert L. Trask (Eds.), Towards a history of the Basque language (pp. 101-135). Ámsterdam: John Benjamins. Minsheu, John (1617). Ductor in linguas (Guide into the tongues) and Vocabularium hispanicolatinum. Londres: John Brownes.

Mir, Miguel (1866). El estado o punto de perfección a que lograron levantar la lengua española los autores de los dos últimos tercios del siglo XVI y primero del XVII. Discursos leídos ante la Real Academia Española en la recepción pública del R. P. Miguel Mir. Madrid: Tipografía de los Huérfanos.

Monroy, Rafael (1865). Estudios ortográfico-prosódicos sobre la reforma que admiten la escritura y pronunciacion castellanas. Barcelona: Juan Bastinos e hijo.

Moreno Fernández, Francisco (2005). Principios de sociolingüística y sociología del lenguaje (2a. ed.). Barcelona: Ariel.

Moreno Soldevila, Rosario (2006). Martial, book Iv: a commentary. Leiden: Brill. Muñoz Álvarez, Agustín (1828 [1793]). Gramática de la lengua castellana (5a. ed.). Sevilla: Imprenta de Hidalgo y Compañía.

Muñoz Pena, Pedro (2010 [1872]). Discurso sobre el origen y progreso de la lengua castellana. Edición de Pilar Díez de Revenga Torres \& Miguel Ángel Puche Lorenzo. Murcia: Universidad de Murcia. Navarro Tomás, Tomás (1999 [1932]). Manual de pronunciación española (4a. ed.). Madrid: Consejo Superior de Investigaciones Científicas. Navarro Tomás, Tomás (1933). La frontera del andaluz. Revista de Filología Española, 20, 1933, pp. 225-277. 
Navarro Tomás, Tomás (1935). El acento castellano. Discurso leído por el autor en el acto de su recepción académica el día 19 de mayo de 1935. Madrid: Tipografía de Archivos, Olózaga, 1.

NGRAE = Real Academia Española \& Asociación de Academias de la Lengua Española (2011). Nueva gramática de la lengua española: fonética y fonología. Madrid: Espasa.

Ortega Cantero, Nicolás (2009). Paisaje e identidad: la visión de Castilla como paisaje nacional (1876-1936). Boletín de la Asociación Española de Geografía, 51, 25-49. https://bage.age-geografia.es/ojs/index.php/ bage/article/view/1131

Ortiz de Pinedo Sánchez, Núria (2017). Análisis acústico de las vibrantes del español en habla espontánea (Tesis doctoral inédita). Universitat de Barcelona, Barcelona. https://www.tdx.cat/handle/10803/454817\#pa $\mathrm{ge}=1$

Poch Olivé, Dolores (2018). La “entraña fonética del español” según Tomás Navarro Tomás. En María L. Arnal Purroy, Rosa M. Castañer Martín, José M. Enguita Utrilla, Vicente L. Gracia \& María A. Martín Zorraquino (Eds.), Actas del x Congreso Internacional de Historia de la Lengua Española, Zaragoza, 7-11 de septiembre de 2015 (Vol. 1, pp. 411-425). Zaragoza: Institución Fernando el Católico.

Poyatos, Fernando (1994). La comunicación no verbal II: Paralenguaje, kinésica e interacción. Madrid: Istmo.

Quilis, Antonio (1999). Tratado de fonología y fonética españolas (2a. ed.). Madrid: Gredos.

Real Academia Española (rae) (1803). Diccionario de la lengua castellana compuesto por la Real Academia Española, reducido a un tomo para su más fácil uso (4a. ed.). Madrid: Viuda de Ibarra.

Real Academia Española (Rae) (1837). Diccionario de la lengua castellana (8a. ed.).

Madrid: Imprenta nacional.

Rodríguez, Cristóbal (1738). Bibliotheca universal de la polygraphia española.

Madrid: Antonio Marín.

Rodríguez Aniceto, Cipriano (1931). Contribución al estudio de los textos latinos de la Edad Media española. El poema latino "Prefacio de Almería". Boletín de la Biblioteca de Menéndez Pelayo, 13, 140-175.

Rohlfs, Gerhard (1970). Le gascon: étude de philologie pyrénéenne (2a. ed.). Tubinga: Max Niemeyer. 
Sánchez Manzanares, María del Carmen (2019). La unidad del idioma y otras ideologías lingüísticas en las columnas sobre la lengua de Álex Grijelmo. En Carmen Marimón Llorca \& M. Isabel Santamaría Pérez (Eds.), Ideologías sobre la lengua y medios de comunicación escritos: el caso del español (pp. 217-234). Berlín: Peter Lang.

Stevens, John (1706). A New Spanish and English dictionary. Londres: George Sawbridge.

Terracini, Lore (1992). Alabanza de lengua, menosprecio de gente, en la cultura lingüística española de los Siglos de Oro. En Antonio Vilanova (Ed.), Actas del x Congreso de la Asociación Internacional de Hispanistas, Barcelona, 21-26 de agosto de 1989 (pp. 55-76). Barcelona: Promociones y Publicaciones Universitarias.

Trask, Robert Lawrence (1997). The History of Basque. Londres: Routledge.

Trittin, Pamela Jean \& de Santos y Lleó, Andrés (1995). Voice quality analysis of male and female Spanish speakers. Speech Communication, 16, 359-368. von Humboldt, Wilhelm (1836). Über die Verschiedenheit des menschlichen Sprachbaues und ihren Einfluss aus die geistige Entwickelung des Menschengeschlechts. Berlín: [s.n. pero imprenta de la Real Academia de las Ciencias].

Zamora Salamanca, Francisco José (2008). Cuatro encuestas prosódicas en Castilla y León (algunas reflexiones sobre prosodia y dialectología diacrónicas en el espacio lingüístico castellano-leonés). Comunicación presentada en el Xv Congreso Internacional de la Asociación de Lingüística y Filología de América Latina (ALFAL), celebrado del 18 al 21 de agosto de 2008 en Montevideo. 